\title{
A UTILIZAÇĀO DO SILICATO BIOQUIMICAMENTE MODIFICADO NOS MECANISMOS DAS MANIFESTAÇÕES PATOLÓGICAS AUMENTANDO A VIDA ÚTIL DAS ESTRUTURAS DE CONCRETO ARMADO
}

\author{
COUTINHO, LEONARDO \\ Engenheiro Civil Msc \\ UFRJ \\ RJ; Brazil \\ leonardo.coutinho@tecnorap.com.br
}

\begin{abstract}
RESUMO
O presente artigo tem como objetivo analisar e apresentar as diversas utilizações e proteções do silicato bioquimicamente modificado no aumento da vida útil das estruturas de concreto armado em condições de severa agressividade. O silicato bioquimicamente modificado se associa ao cálcio livre do concreto e toda vez que entra em contato com a umidade, reage quimicamente resultando na formação de um gel C-S-H dentro do concreto, que ao expandir veda poros vazios e capilares dentro da estrutura, protegendo-a e atuando no mecanismo de diversas manifestações patológicas que necessitam do cálcio livre do concreto para ocorrer. Ao se incorporar à estrutura de concreto armado, o silicato bioquimicamente modificado proporciona propriedades regenerativas definitivas (autocicatrizantes) à estrutura, uma vez que sempre que entrar em contato com a umidade sua reação química dentro do concreto faz com que o gel C-S-H formado, se expanda conforme a estrutura necessite, ou seja, por formar um gel, a sua reação acompanha as características de porosidade e fissuração da estrutura, preenchendo os vazios necessários para proteção da estrutura de concreto e atuando em um dos principais fatores geradores de manifestações patológicas na estrutura, o cálcio livre. $\mathrm{O}$ aumento da vida útil da estrutura, a sua proteção contra as principais manifestações patológicas em estruturas de concreto e a sustentabilidade que esse sistema proporciona há mais de 40 anos no mercado mundial para as estruturas de concreto armado são pilares bastante relevantes para a contribuição do desenvolvimento da boa técnica na engenharia brasileira.

Palavras-chave: patologia, silicato bioquimicamente modificado, proteção de concreto, mecanismos de degradação, manifestações patológicas.
\end{abstract}

\section{ABSTRACT}

The present article aims to analyze and present the various uses and protections of biochemically modified silicate in increasing the lifetime of reinforced concrete structures under conditions of severe aggressiveness. Biochemically modified silicate associates with the free calcium of the concrete and every time it comes in contact with moisture, it reacts chemically resulting in the formation of a CSH gel inside the concrete, which by expanding seals voids and capillary pores inside the structure, protecting it and acting in the mechanism of several pathological manifestations that require the free calcium of the concrete to occur. By incorporating into the reinforced concrete structure, biochemically modified silicate provides definitive regenerative (self-healing) properties to the structure, since whenever it comes in contact with moisture its chemical reaction inside the concrete causes the formed CSH gel, expanding as the structure requires, by forming a gel, its reaction follows the characteristics of porosity and cracking of the structure, filling the voids needed to protect the concrete structure and acting on one of the main factors generating pathological manifestations in the structure. structure, the free calcium. The significant increase in the structure lifetime, its protection against major pathological manifestations in concrete structures and the sustainability that this system provides for over 40 years in the world market for reinforced concrete structures are very important pillars for the contribution of the development of the concrete protection at the Brazilian engineering.

Keywords: concrete patology, biochemicaly modified silicate, concrete protection, mechanism of degradation, pathological manifestation. 


\section{INTRODUÇÃO}

As estruturas de concreto armado são amplamente utilizadas como pilares fundamentais no desenvolvimento da economia e da sociedade como um todo, desde estruturas residenciais, comerciais, industriais e infra-estrutura. Sua aplicação é muito bem aceita devido ao seu excelente custo-benefício, onde a sua vida útil é um fator determinante para o sucesso. Desta forma, é fundamental que o comportamento da estrutura ocorra de forma que atenda a vida útil mínima de projeto e consequentemente a viabilidade econômico-financeira do empreendimento.

A fim de atender a expectativa de uma vida útil de projeto adequada, há que ser ter bastante critério no projeto, principalmente levando em consideração qual é o tipo de estrutura a ser projetada e qual é a agressividade a que ela está submetida. Porém, apenas o projeto não é suficiente para que a estrutura atinja a vida útil de projeto confome projetado, nesse caso, a execução também possui papel fundamental para atingir o sucesso do que fora projetado. Portanto o momento da concretagem da estrutura, é crucial e deve-se ter um cuidado especial com o adensamento do concreto através de uma correta vibração e após a concretagem deve-se obedecer criteriosamente a sua cura. Entretanto, mesmo obedecendo e realizando os procedimentos corretamente, a estrutura de concreto recentemente concretada, pode se apresentar de forma irregular e variável e principalmente estando em ambientes de severa agressividade, as fraquezas e deficiências da estrutura estarão sendo reveladas em um curtíssimo espaço de tempo, independentemente da qualidade do projeto de vida útil e dos materiais utilizados (GJORV, 2015).

A fim de manter a durabilidade das estruturas de concreto, deve-se analisar tanto os fatores externos, ambiente em que está inserida a estrutura, quanto os fatores internos, sua composição química. Os mecanismos de atuação dos principais agressores externos serão analisados, mas na microestrutura do concreto armado existem três fatores que são fundamentais e influenciam muito no processo da sua degradação, são eles: a porosidade do concreto, o cálcio livre presente na estrutura após a hidratação do cimento e água proveniente do ambiente. Esses três atores são os principais responsáveis no aparecimento da grande maioria das manifestações patológicas nas estruturas de concreto, influenciando e reduzindo a sua vida útil, elevando consideravelmente o seu custo de manutenção, afetando diretamente o planejamento financeiro do custo-benefício relacionado à vida útil do empreendimento. Portanto, é fundamental proteger a estrutura de concreto armado a fim de atingir uma vida útil cada vez maior, e dependendo das condições ambientais e do local onde a estrutura de concreto armado esteja inserida, há uma maior ou menor necessidade de proteção da estrutura, pois a agressividade no concreto varia conforme o meio em que ela está inserida.

Existem diversas técnicas que permitem proteger as estruturas da agressividade externa, a maioria das proteções estão associadas à parte exterior da estrutura de concreto com a utilização de barreiras, normalmente através de membranas ou camadas protetoras, tais como: membrana de poliuretano, epoxi, aumento do cobrimento da estrutura, entre outros. Entretanto, também existem proteções internas, utilizadas dentro da estrutura de concreto, como a utilização de pastilhas de zinco para proteção catódica, materiais à base de silicatos que reagem com o concreto entre outros.

Todas essas proteções utilizadas nas estruturas de concreto são provenientes de ensaios e estudos relacionados às estruturas de concreto onde a capacidade de proteção e a vida útil de cada solução deve ser criteriosamente analisada, pois, dependendo por exemplo da sua vida útil, há a necessidade de reaplicação desta proteção, que não interfere somente no custo do material e mão-de-obra empregados no processo e sim, principalmente em casos de áreas industriais, na necessidade de paralização do processo produtivo para poder proteger novamente a estrutura na qual a sua proteção fora comprometida, causando prejuízos multimilionários. GJORV (2015) informa que cada vez mais os proprietários de estruturas de concreto perceberam que pequenos custos adicionais relacionados ao projeto e à execução demonstraram impactar de sobremaneira a durabilidade e vida útil das estruturas, se tornando um excelente investimento.

Essa preocupação com a viabilidade econômica relacionada a vida útil das estruturas não é recente, de acordo com MCBEE (1983), em seu relatório para o Departamento de Interior dos Estados Unidos, o ataque químico do sulfato no concreto armado nos Estados Unidos, traz anualmente prejuízos multimilionários em plantas industriais de metalurgia, de fertilizantes e de produtos químicos, devido à perda de produtividade causadas por manutenções e reparos ocasionados pelo ataque de sulfatos nas estruturas de concreto armado.

É notória a importância da proteção das estruturas de concreto e a sua relação direta com o processo produtivo industrial, podendo interferir diretamente nos resultados financeiros da empresas e se formos analisar mais profundamente, centenas de pesquisadores e todo o meio acadêmico possuem preocupação relacionado à proteção das estruturas de concreto e ao consideramos que o estudo feito por MCBEE (1983) contempla apenas as perdas 
relacionadas somente ao ataque de sulfatos em 1983, verifica-se a enorme relevância da proteção des estruturas de concreto armado.

Desta forma, esse trabalho busca apresentar alguns dos principais mecanismos de degradação das estruturas de concreto armado, tais como o ataque de cloretos, o ataque de sulfatos e como a solução de silicatos bioquimicamente modificados atua se incorporando completamente na estrutura de concreto e fazendo parte da sua composição química, é capaz de proporcionar diversos benefícios protetivos à estrutura em que tiver sido aplicado. Conforme será apresentado nesse artigo, existem diversos ensaios e comprovações da atuação do silicato bioquimicamente modificado e dos benefícios proporcionados por essa solução técnica, que são bastante representativos e apesar de estar incorporado à estrutura química do concreto e sua reação química com o concreto não poder ser vista a olho nu, os resultados de longo prazo de sua proteção são claramente visíveis e compovados com ensaios laboratoriais.

Portanto, este artigo, ao contemplar essa solução, busca apresentar as principais causas de manifestações patológicas e entendendo como o mecanismo delas funciona é possível atuar na origem do processo de degradação, muitas vezes antes mesmo que ele ocorra. Ao conseguir atuar no mecanismo do processo de degradação, há um aumento imediato e efetivo na vida útil das estruturas de concreto armado, trazendo vultuosos benefícios econômico-financeiros para a sociedade e para a engenharia como um todo.

\section{MECANISMOS DE DEGRADAÇÃ̃O}

As manifestações patológicas das estruturas de concreto armado nada mais são do que o resultado final de todo o processo físico-químico relacionado ao meio em que a estrutura de concreto está inserida, portanto é fundamental realizar a patologia, ou seja estudar os motivos pelos quais a estrutura reage com o meio em que está inserida e para isso é primordial entender os mecanismos de degradação das estruturas de concreto armado, pois essa é a origem de todo esse processo. Portanto a seguir serão apresentados os mecanismos de degradação relacionados ao ataque da carbonatação, ataque de cloretos e ao ataque de sulfatos nas estruturas de concreto armado.

\subsection{Carbonatação}

A carbonatação é um dos principais fatores, senão o principal fator deletério à redução do PH na estrutura que ao se aprofundar dentro do concreto, a frente de carbonatação chega na profundidade da armadura acabando com a proteção externa, e quando PH está próximo de 9, o concreto permite que se inicie o processo de despassivação do aço e consequentemente seu processo de corrosão.

Sua reação química está expressa na equação (1), onde o gás carbônico reage com a água, formando ácido carbônico, que ao reagir com o hidróxido de cálcio da pasta de cimento forma o carbonato de cálcio e água, disponibilizando mais água para reagir com o gás carbônico, permitindo asism que a frente de carbonatação se aprofunde cada vez mais na estrutura reduzindo o seu $\mathrm{PH}$ até alcançar a profundidade do aço, permitindo assim o início do processo corrosivo.

$$
\begin{array}{r}
\text { (1) } \mathrm{CO}_{2}+\mathrm{H}_{2} \mathrm{O} \rightarrow \mathrm{H}_{2} \mathrm{CO}_{3}+\mathrm{Ca}(\mathrm{OH})_{2} \rightarrow \mathrm{CaCO}_{3}+\mathrm{H}_{2} \mathrm{O} \\
\text { Ácido Carbônico Carbonato de Cálcio }
\end{array}
$$

\subsection{Ataque por cloretos}

No processo de corrosão por ataque de cloretos há de se considerar que a sua incidência somente acontecerá após a despassivação da camada passivadora do aço, que por sua vez está protegida pelo alto valor do PH que a estrutura de concreto proporciona, portanto caso o PH permaneça com valores de 12,3 a 13,5 (NEVILLE, 1997), que são os valores que o concreto assume sem nenhuma agressividade, não ocorreá a oxidação do aço. Entretanto, diversos são os agentes agressivos nas estruturas de concreto, entre eles o cloreto, cuja reação química do íon cloro com a água, forma o ácido clorídrio, expresso na equação (2), que possui a capacidade de reduzir o PH do concreto.

$$
\text { (2) } \mathrm{Cl}^{-}+\mathrm{H} 2 \mathrm{O} \rightarrow \mathrm{HCl}+\mathrm{O}_{2}
$$

ácido clorídrico 
Após o início da corrosão do aço, com a oxidação, o aço expande, gerando tensões internas que podem causar fissuras e desplacamento do concreto, acelerando ainda mais o processo corrosivo. Buscando proteger a vida útil de serviço das estruturas de concreto inseridas em agressividade com ataque de cloreto são utilizadas diversas soluções técnicas, entre elas: aumento do cobrimento da armadura, utilização de membranas aderidas à face externa da estrutura de concreto, adições utilizadas na mistura da massa de cimento, adições aplicadas posteriormente a concretagem, além de proteções capazes de absorver as cargas geradas postergando o processo de corrosão da armadura, como a aplicação de um potencial elétrico externo para extração de íons de cloro, desenvolvendo um mecanismo de migração (FERREIRA, 2000).

HELENE (2003) apresenta a importância da difusão de cloretos em faces externas de componentes estruturais de concreto armado expostos à agressividade do ataque de cloretos relacionando a espessura do cobrimento de concreto da armadura, a idade da estrutura e a sua resitência a compressão, pois quanto maior for a resistência à compressão da estrutura, maior tenderá a ser a sua densidade, com menor porosidade e índice de vazios, dificultando a penetração e locomoção de agentes agressivos no interior da estrutura de concreto armado, proporcionando uma maior proteção nas armaduras. Desta forma, a fim de se projetar determinada vida útil de estruturas de concreto armado, é extremamente relevante analisar o impacto no custo-financeiro do empreendimento entre alterar a espessura do cobrimento das armaduras ou alterar a resistência do concreto a fim de atingir a vida útil de projeto.

A redução do $\mathrm{PH}$ da estrutura de concreto, propicia o ambiente adequado para a penetração de mais íons de cloro que irão atuar no processo corrosivo das armaduras, conforme a equação (3) (NEVILLE, 1997).

$$
\mathrm{Fe}^{++}+2 \mathrm{Cl}^{-} \rightarrow \mathrm{FeCl}_{2}
$$

(3) $\mathrm{FeCl}_{2}+2 \mathrm{H}_{2} \mathrm{O} \rightarrow \mathrm{Fe}(\mathrm{OH})_{2}+2 \mathrm{HCl}$

$\mathrm{O}$ ataque de cloreto nas estruturas de concreto armado é um dos principais agentes deletérios e gera anualmente custos da ordem de centenas de milhões de reais para realizar as recuperações estruturais necessárias. Principalmente relacionados à falta de monitoramento e manutenção nas estruturas de concreto, pois não realizando as manutenções preventivas e deixando apenas para realizar intervenções corretivas os custos chegam a ser da ordem de 25 vezes a mais do que se fossem realizadas as manutenções preventivas (SITTER, 1983).

\subsection{Ataque por sulfatos}

A ação deletéria do ataque de sulfatos nas estruturas de concreto pode ser considerado também um dos principais agentes deteriorantes dessas estruturas, que pode ser encontrado em águas naturais, no solo, no mar, em efluentes industriais, esgotos, entre outros (COSTA, 2004).

$\mathrm{O}$ ataque do íon sulfato ( $\mathrm{SO}_{4}{ }^{2-}$ ) ocorre nas estruturas de concreto tanto saturadas, por difusão, quanto seco, por absorção. Os íons sulfato ( $\mathrm{SO}_{4}{ }^{2-}$ ) ao reagir com o cálcio, potássio, sódio e magnésio provenientes dos materiais presentes no concreto, no solo ou presentes na água, formam os sulfatos. Os diferentes tipos de sulfatos deterioram o concreto, entretanto a sua agressividade e mecanismos dependem do tipo de sulfato que está sendo analisado. De acordo com CESÁRIO (2015), o sulfato associado à água penetra pelos poros da pasta de cimento endurecida, reagindo com os compostos da hidratação do cimento, formando compostos como etringita $\left(\mathrm{Ca}_{6} \mathrm{Al}_{2}(\mathrm{OH})_{12} *\left(\mathrm{SO}_{4}\right)_{3} * 26 \mathrm{H}_{2} \mathrm{O}\right)$ e gipsita $\left(\mathrm{CaSO}_{4} * 2 \mathrm{H}_{2} \mathrm{O}\right)$. Esses dois compostos têm a característica de ocupar um volume maior que o composto original, isso ocasiona tensões internas no concreto que acaba fissurando, permitindo assim que maior quantidade de sulfatos penetrem na estrutura, além de outros agentes agressivos como a água, os cloretos $\left(\mathrm{Cl}^{-}\right)$e gás carbônico $\left(\mathrm{CO}_{2}\right)$.

De acordo com COUTINHO (2001), o ataque de sulfatos ao concreto necessitam do hidróxido de cálcio e da água para poder reagir com o aluminato tricálcico ou com o óxido de alumínio do agregado para resultar na etringita, na gispista e no sulfoaluminato de cálcio hidratado, formando um composto com volume final 2,5 vezes maior que o volume inicial, causando tensões internas, fissuração irregular do concreto, acelerando ainda mais a deterioração da estrutura.

CENTURIONE (2003), é taxativo ao afirmar que:

"Existe unanimidade em aceitar que o aumento do teor de escória ou pozôlana leva a aumento da resistência aos sulfatos do concreto.

Essa maior resistência é atribuída principalmente a: 
a) combinação da escória ou da pozôlana, com o hidróxido de cálcio, formando C-S-H e deixando menor quantidade de $\mathrm{Ca}(\mathrm{OH})_{2}$ livre;

b) refinamento da estrutura dos poros, dificultando a difusibilidade iônica;

c) modificação da química do sistema, com formação de monosulfoaluminato no lugar de etringita, e conseqüentemente com expansão insignificante."

Entendendo que o ataque de sulfatos proveniente de esgotos é um fator de extrema importância a ser analisado, o seu mecanismo será apresentado no item 2.2.1.

\subsubsection{Ataque por sulfatos no esgoto}

$\mathrm{O}$ ataque de sulfatos $\left(\mathrm{SO}_{4}^{-2}\right)$ gerados pelo esgoto sanitário possui severa agressividade à integridade das estruturas de concreto armado e sua importância é bastante relevante, uma vez que a maioria das cidades possui um sistema de saneamento básico e o impacto dessa agressividade nas instalações de tratamento de efluentes e principalmente nas tubulações que interligam o sistema, caso falhem, podem impactar na vida de milhares de pessoas, gerando custos diretos e indiretos da ordem de milhões de reais.

A vida útil de um sistema de abastecimento de água ou de coleta de águas pluviais ou esgoto deve ser tomado como de extrema importância e cuidado, pois o custo da sua implementação é bastante alto, demorado e acaba interferindo diretamente no fluxo viário das cidades com escavações e outras intervenções, alterando assim os hábitos de deslocamento das pessoas por um tempo considerável. Todos esses custos indiretos deveriam ser levados em consideração no momento da escolha da solução técnica que deve ser utilizada para proteger a estrutura de concreto, pois quanto maior for a vida útil da solução escolhida menor será o custo sentido pela população, uma vez que em alguns casos, os custos indiretos gerados na sociedade e na economia por uma intervenção dessa natureza podem ser até maiores que o próprio custo de implementação da obra. $\mathrm{O}$ que se dirá se essa intervenção estiver relacionada à alguma falha no sistema, gerando uma manutenção corretiva.

Segundo VON SPERLING (2005), o PH do esgoto sanitário se situa na faixa de 6,7 a 8,0, que ocasiona a redução do $\mathrm{PH}$ da estrutura de concreto, permitindo o ataque de outros elementos químicos às armaduras. Além de atuar na redução do PH do concreto, a reação do ácido sulfúrico formado com o hidróxido de cálcio da pasta de cimento, formam a gispsita (4), que reagindo com o aluminato tricálcico e a água forma a etringita (5) (JIANG, 2013). A gipsita e etringita formadas, possuem volume molecular bem maior que seu volume original, da ordem de $124 \%$ a $700 \%$ do seu volume inicial (JIANG, 2013; apud MONTENY 2000), gerando desta forma tensões de tração internas que causam fissuração e desplacamento do concreto, acelerando a ação deletéria do ácido sulfúrico na estrutura de concreto e permitindo que os agentes ácidos deteriorem as armaduras.

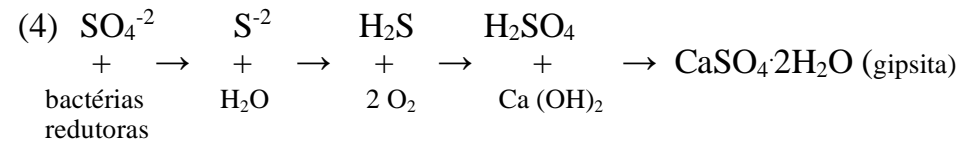

$$
\text { (5) } 3 \mathrm{CaSO}_{4} \cdot 2 \mathrm{H}_{2} \mathrm{O}+4 \mathrm{CaO} \cdot \mathrm{Al}_{2} \mathrm{O}_{3} \cdot 13 \mathrm{H}_{2} \mathrm{O}+14 \mathrm{H}_{2} \mathrm{O} \rightarrow(\mathrm{CaO})_{3} \cdot \mathrm{Al}_{2} \mathrm{O}_{3} \cdot\left(\mathrm{CaSO}_{4}\right)_{3} \cdot 32 \mathrm{H}_{2} \mathrm{O} \text { (etringita) }
$$

É fundamental entender o mecanismo de atuação do esgoto sanitário em sua ação deletéria no concreto armado, pois somente entendendo como funciona e o que ocasiona o ataque do sulfato é possível definir a melhor solução técnica e interferir no aumento da sua vida útil, beneficiando assim toda a sociedade.

\section{MATERIAL E MÉTODOS}

\subsection{Caracerísticas do silicato bioquimicamente modificado}

O silicato bioquimicamente modificado possui como principal característica a reação química com o cálcio livre presente na pasta de cimento e essa reação produz o gel C-S-H, tão importante para manter o concreto são e ao manter o PH do concreto elevado, resguardando assim a passivação das armaduras. A análise com maior profundidade dessa reação química deste material com o cálcio livre do concreto é de extrema importância, pois conforme apresentado anteriormente nos mecanismos deletérios do concreto armado, o hidróxio de cálcio é um fator decisivo na reação 
química da carbonatação e do ataque por sulfatos. Segundo informações fornecidas pelo fabricante, o silicato bioquimicamente modificado penetra até $20 \mathrm{~mm}$ dentro do concreto e reage com o cálcio livre da estrutura de concreto, formando o gel C-S-H que tampona os poros vazios e capilares presentes dentro da estrutura física do concreto impermeabilizando-o. A reação da formação do gel C-S-H é uma reação continua que ocorre sempre que a umidade entra em contato com o composto formado pelo silicato bioquimicamente modificado e o cálcio livre, não permitindo que hidróxido de cálcio esteja disponível em maiores concentrações, dentro de até $20 \mathrm{~mm}$ de profundidade, para reagir com outros compostos químicos deletérios à estrutura de concreto armado.

O silicato bioquimicamente modificado é um líquido que deve ser pulverizado na estrutura de concreto armado curado, que, segundo o fabricante, fornece impermeabilização de longo prazo e durabilidade de estruturas em concreto, que iremos verificar no item 4 (materiais e métodos). Outras informações obtidas junto ao fabricante são que: o silicato bioquimicamente modificado possui um PH igual a 11,7, é atóxico, inodoro, é ambientalmente correto, não gera resíduos, não altera a potabilidade da água, aumenta a resistência do concreto à compressão axial e à abrasão e resiste à agressão de produtos químicos com PH maior que 3,5.

Esse material é utilizado há mais de 40 anos no mercado mundial protegendo, aumentando a vida útil e impermeabilizando diversos tipos de estruturas de concreto, portanto é de fundamental importância realizar ensaios e analisarmos alguns comportamentos e resultados deste material aplicado à estruturas de concreto armado.

\subsection{Procedimentos}

Todos os ensaios e procedimentos foram realizados pelo IPT-SP, conforme apresentado a seguir:

Os materiais utilizados neste trabalho estão apresentados abaixo.

- Água potável fornecida pela Sabesp;

- Cimento Portland composto CPII F 32;

- $\quad$ Agregado miúdo: areia natural de rio;

- $\quad$ Agregado graúdo: pedra britada (Brita 1 e Brita 2);

Neste trabalho foram moldados dois concretos: concreto de referência e concreto para aplicação do silicato bioquimicamente modificado. $O$ traço do concreto utilizado foi de 1:2,44:2,14:1,43:0,6 (cimento:areia:brita 1;brita 2:água), que é recomendado pela norma NBR 12171 - Aderência aplicável em sistema de impermeabilização composto por cimento impermeabilizante e polímeros - Método de ensaio (ABNT, 2018).

\subsection{Métodos}

\subsubsection{Ensaios}

- Resistência à compressão axial: NBR 5739 - Concreto - Ensaio de compressão de corpos de prova cilíndricos (ABNT, 2018);

- Resistência à penetração de íons cloreto: ASTM C1202 - Standard Test Method for Electrical Indication of Concrete's Ability to Resist Chloride Ion Penetration. ASTM, 2018.

\subsubsection{Condições de cura e aplicação do silicato bioquimicamente modificado}

Os corpos de prova foram curados em câmara úmida com umidade de $100 \%$ e temperatura ambiente de, aproximadamente, $22{ }^{\circ} \mathrm{C}$.

As etapas de preparação das amostras para os ensaios são as apresentadas a seguir.

- $\quad$ Etapa 1: Cura por 28 dias;

- $\quad$ Etapa 2: Secagem por 34 dias; 
- Etapa 3: Aplicação superficial do silicato bioquimicamente modificado com um consumo de $200 \mathrm{~mL} / \mathrm{m}^{2}$ (apresentado na Figura 1);

- Etapa 4: Hidratação dos corpos de prova, que foi realizada após secagem do silicato bioquimicamente modificado (aproximadamente 3 horas);

- Etapa 5: Aplicação de agente acelerador à base hidróxido de cálcio, que foi realizada por borrifação 24 horas após a hidratação dos corpos de prova;

- Etapa 6: Cura dos corpos de prova por 28 dias. Os corpos de prova de referência (sem aplicação de silicato bioquimicamente modificado) foram ensaiados com a mesma idade das amostras com a aplicação do silicato bioquimicamente modificado;

A nomenclatura da amostra do concreto de referência é 306-19 REF (sem proteção) e a nomenclatura da amostra onde o silicato bioquimicamente modificado foi aplicado é 306-19 (protegido).

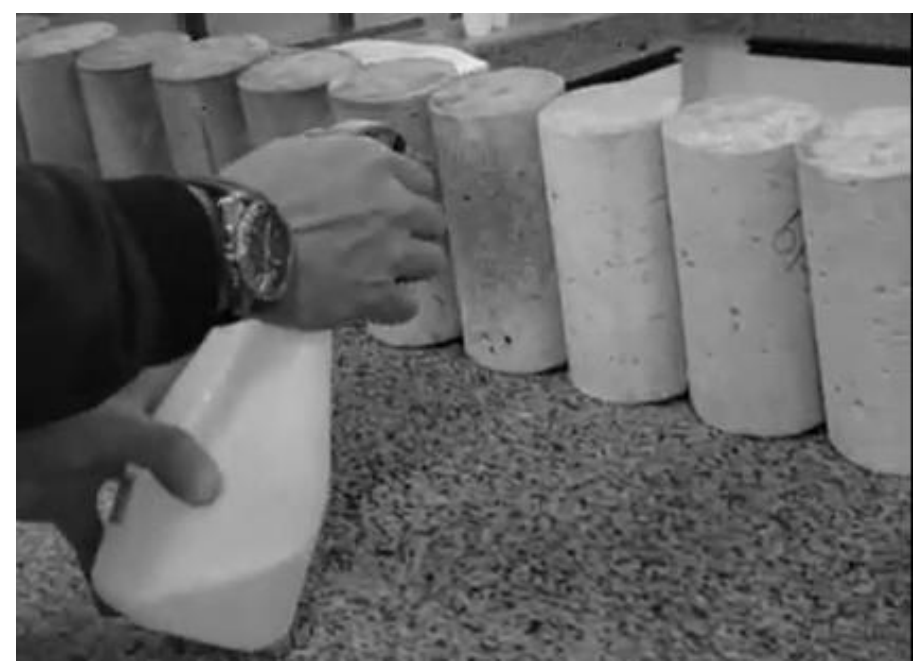

Figura 1 - Aplicação do silicato bioquimicamente modificado

\section{RESULTADOS E DISCUSSÕES}

\subsection{Resultados}

4.1.1. Propriedades do concreto no estado fresco

A Tabela 1 apresenta as seguintes propriedades do concreto no estado fresco: abatimento, massa específica e teor de ar incorporado).

Tabela 1 - Propriedades do concreto no estado fresco

\begin{tabular}{|l|r|}
\hline & Resultados \\
\hline Slump (NBR NM 67) (ABNT, 1998) & $15 \mathrm{~mm}$ \\
\hline & 2.200 \\
Massa específica (NBR 9833) (ABNT, 2008) & $\mathrm{kg} / \mathrm{m}^{3}$ \\
\hline Teor de ar incorporado & $1,40 \%$ \\
\hline
\end{tabular}

\subsubsection{Propriedades do concreto no estado endurecido}

\subsubsection{Resistência à compressão axial}

O ensaio de compressão axial, foi realizado de acordo com a NBR 5739 - Concreto - Ensaio de compressão de corpos de prova cilíndricos (ABNT, 2018), com os resultados apresentados na Tabela 2. 
Tabela 2 - Resistência à compressão axial

\begin{tabular}{|c|r|r|}
\hline $\begin{array}{c}\text { Resistência à } \\
\text { compressão axial } \\
\text { Amostra }\end{array}$ & CP's & \multicolumn{1}{c|}{$\begin{array}{c}\text { Resistência à } \\
\text { compressão axial } \\
\text { (MPa) }\end{array}$} \\
\hline \multirow{3}{*}{$306-19-$ REF } & 1 & 26,33 \\
\cline { 2 - 3 } & 2 & 23,58 \\
\cline { 2 - 3 } & 3 & 26,73 \\
\hline \multirow{3}{*}{$306-19$} & 4 & 33,56 \\
\cline { 2 - 3 } & 5 & 36,11 \\
\cline { 2 - 3 } & 6 & 35,17 \\
\hline
\end{tabular}

A Figura 2 apresenta a média dos resultados obtidos no ensaio de compressão axial, onde pode-se concluir um aumento médio de 37\% (aproximadamente 10MPa) na resistência do corpo de prova à compressão axial. Desta forma, um corpo de prova que possui uma resistência à compressão média de 25,5 Mpa, após aproximadamente um mês da aplicação do silicato bioquimicamente modificado teve como resultado médio a compressão de $34,95 \mathrm{MPa}$, praticamente um comportamento de um corpo de prova de $35 \mathrm{MPa}$.

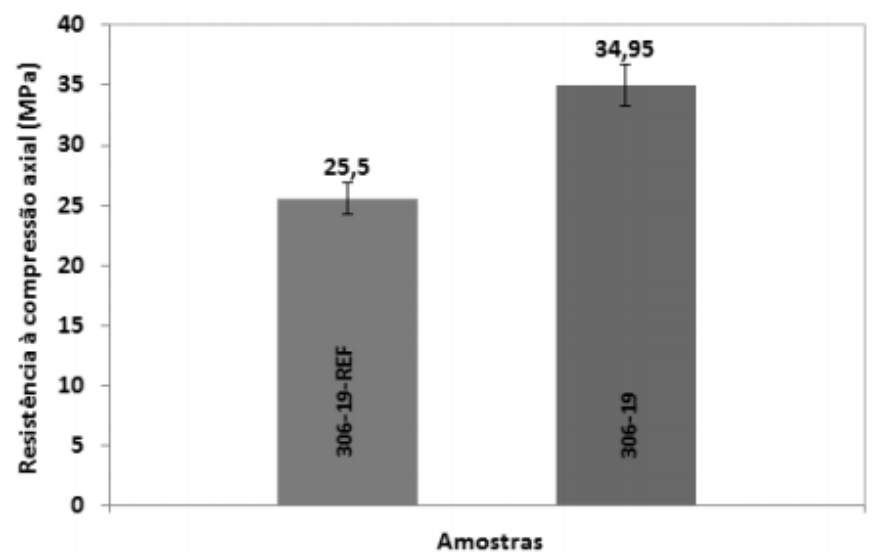

Figura 2 - Resistência à compressão axial.

\subsubsection{Resistência à penetração de íons cloreto}

O ensaio de resistência à penetração de íons cloreto conforme a ASTM C1202 - Standard Test Method for Electrical Indication of Concrete's Ability to Resist Chloride Ion Penetration. ASTM, 2018, foi realizado a fim de apresentar o comportamento do silicato bioquimicamente modificado incorporado ao concreto visando a proteção de estruturas de concreto armado inseriadas em ambientes com alta concentração de cloretos.

A Tabela 3 apresenta a resistência à penetração dos íons cloreto $\left(\mathrm{Cl}^{-}\right)$no concreto, no corpo de prova de referência e no corpo de prova com aplicação do silicato bioquimicamente modificado, expresso em cargas passantes (Coulombs).

Tabela 3 - Resultados dos ensaios, em carga elétrica passante (Coulombs)

\begin{tabular}{|l|r|r|r|}
\hline \multirow{2}{*}{$\begin{array}{c}\text { Identificação das } \\
\text { amostras }\end{array}$} & \multicolumn{3}{|c|}{ Resultados, em Coulombs (C) } \\
\cline { 2 - 4 } & Ensaio A & \multicolumn{1}{|c|}{ Ensaio B } & Média \\
\hline 306-19-REF & 6292 & 6307 & 6300 \\
\hline $306-19$ & 3502 & 2305 & 2904 \\
\hline
\end{tabular}

A Tabela 4 apresenta os limites de carga passante em Coulombs, indicados na norma ASTM C1202 (ASTM, 2018), segundo o grau de agressividade em que estão inseridas, para a classificação do concreto quanto à penetrabilidade a íons cloreto. 


\begin{tabular}{|c|c|}
\hline $\begin{array}{l}\text { Carga passante, } \\
\text { em Coulombs (C) }\end{array}$ & $\begin{array}{c}\text { Classificação do concreto quanto } \\
\text { à penetrabilidade a íons cloreto } \\
\text { (de acordo com a ASTM C } \\
1202: 2018)\end{array}$ \\
\hline$>4000$ & Elevada \\
\hline $2000-4000$ & Moderada \\
\hline $1000-2000$ & Baixa \\
\hline $100-1000$ & Muito baixa \\
\hline$<100$ & Desprezível \\
\hline
\end{tabular}

\subsection{Discussões}

Os resultados obtidos através do ensaio de compressão axial são bastante relevantes, pois um aumento de praticamente $10 \mathrm{MPa}$, ou 37\%, na resistência do corpo de prova à compressão axial com a aplicação do silicato bioquimicamente modificado é fundamental para diversas aplicações, principalmente com relação à estruturas de concreto armado que foram concretadas e não atingiram a resistência a compressão de projeto, pois ao invés de realizar uma intervenção mais profunda na estrutura para atingir determinada resistência, essa solução poderia ser uma alternativa a ser considerada. É lógico que mais estudos e estudos mais aprofundados sobre a ação desse material com o concreto devem ser realizados, mas esse resultado já é um indicativo que essa pode ser uma solução bastante viável para aumentar a resistência à compressão de algumas estruturas de concreto, ao invés de ter que realizar um tratamento com uma intervenção bem mais agressiva ou mais custosa para adquirir a resistência de projeto necessária.

Quando se fala em severa agressividade em estruturas de concreto armado, diversos autores entendem que o primeiro fator a ser analisado com relação à durabilidade de estruturas de concreto é a resistência à compressão, pois esse é o primeiro parâmetro indicativo de como está formada a composição física do concreto, quanto maior a porosidade, índice de vazios, fissuras e microfissuras presentes na estrutura de concreto, menor tenderá a ser a sua resistência à compressão. Portanto, autores como MOREIRA (2001), apresentam que é de fundamental importância a análise da resistência a compressão das estruturas de concreto armado inseridas em ambientes de severa agressividade, são o fator primordial para qualquer estudo ligado ao ataque químico nas estruturas de concreto, e dependendo do ataque, pode comprometer até $60 \%$ da capacidade dos corpos de prova de referência.

Portanto, o desempenho de resistência à compressão axial causado pelo silicato bioquimicamente modificado é bastante relevante quanto a proteção que possa proporcionar a ambientes de severa agressividade, devendo ser realizados mais estudos quanto a sua atuação em corpos de prova com diferentes resistências à compressão axial e como este mateiral altera a permeabilidade, absorção de água, índice de vazios e massa específica, pois também são fatores que possuem influência direta na propagação da frente de agressividade onde a estrutura de concreto armado está inserida.

O hidróxido de cálcio presente na pasta de cimento, é um dos principais fatores que permitem que o meio ambiente com severa agressividade possa ao entrar em contato com o concreto, atuando direta ou indiretamente para propiciar que o meio externo degrade a estrutura de concreto armado. Alguns estudos nesse sentido já foram realizados e mostraram que materiais que reagem com o hidróxido de cálcio e indisponibilizam o cálcio para novas reações, proporcionam uma melhoria na estrutura interna do concreto pois a redução ou retirada do hidróxido de cálcio livre acabam por impedir ou reduzir drasticamente o ataque agressivo na estrutura de concreto armado. NEVILLE (1997), mostra que a utilização de pozôlanas acaba por fixar o hidróxido de cálcio da pasta de cimento, que está presente na maioria das reações químicas de ataque ácido às estruturas de concreto, conforme apresentado anteriormente. Portanto o silicato bioquimicamente modificado, ao se associar com o cálcio livre do concreto e com a umidade formando o gel CS-H dentro da estrutura interna do concreto, reduz drasticamente a disponibilidade do hidróxido de cálcio livre da pasta de cimento, não permitindo que este reaja com a agressividade externa.

Em LAFIN (2015) é possível verificar o estudo de caso da aplicação do silicato bioquimicamente modificado em uma estação de tratamento de esgoto e a opção pela sua utilização ocorreu devido não somente ao seu trabalho de impermeabilização da estrutura de concreto armado, mas também pela proteção proporcionada pela sua proteção contra $o$ ataque de sulfatos. 
Outro fator bastante importante a ser analisado e estudado relacionado ao silicato bioquimicamente modificado é que por possuir um PH elevado igual a 11,7, ele proporciona o ambiente necessário para proteger e alcalinizar ainda mais a estrutura de concreto armado, mantendo a passividade das armaduras, consequentemente aumentando a sua vida útil, reduzindo a necessidade de manutenções, melhorando assim o custo-benefício do empreendimento.

Relativo ao ataque de cloretos no concreto armado, o resultado obtido na Tabela 4, mostra que há uma sensível redução na penetração das cargas passantes na estrutura de concreto de aproximadamente $46 \%$, ou seja, segundo a norma ASTM C1202 (ASTM, 2018), que classifica o concreto quanto à penetrabilidade a íons cloreto, uma estrutura que esteja inserida em um ambiente de elevada agressividade, onde a carga passante em Coulombs seja maior que 4.000, ao utilizar a proteção do silicato bioquimicamente modificado, poderia ser projetada considerando uma agressividade moderada, onde a carga passante em Coulombs é maior que 2.000 e menor que 4.000 Coulombs. Podendo desta forma influenciar no cobrimento ou na resistência do projeto da estrutura de concreto armado. Novamente, estudos mais aprofundados devem ser realizados para entender melhor o comportamento dessa solução à base de silicatos, mas resultados em estudos de casos e ensaios realizados em obras no Brasil e fora do Brasil apresentam benefícios e desempenhos protetivos de longo prazo evidentes às estruturas de concreto armado, melhorando de sobre maneira seu desempenho e aumento de vida útil.

\section{CONCLUSÃO}

A utilização do silicato bioquimicamente modificado nos corpos de prova analisados se mostrou bastante eficaz relacionado às melhorias de seu desempenho e proteções causadas na estrutura de concreto armado, como por exemplo, o aumento de $37 \%$ na resistência à compressão axial e a sua capacidade de difusão de $46 \%$ dos íons cloreto, proporcionando até a redução da classe de agressividade do ambiente, de elevada para moderada, conforme a classificação da ASTM C1202 (ASTM, 2018).

Por ser um material líquido, podendo ser utilizado nas mais diversas idades das estruturas de concreto e a sua reação química com o concreto se basear na associação ao hidróxido de cálcio e formação do gel C-S-H, que expande conforme o contato com a água, essa solução pode ser utilizada nas mais diversas estruturas de concreto armado, tanto para impermeabilização quanto para a proteção de longo prazo das mesmas, reduzindo a necessidade de intervenções para manutenção, melhorando o desempenho em uso dessas estruturas, trazendo desta forma um melhor custo-benefício para o empreendimento.

Estudos mais aprofundados e comparativos à outros materiais relativos à agressividade e ao desempenho devem ser realizados, como por exemplo: ataque de cloretos, ataque de sulfatos, reação álcali-agregados, ataque de uréia, carbonatação, lixiviação, penetração de água, entre outros. Esta solução analisada apresenta diversas catarcerísticas que valem a pena ser estudadas com maior profundidade, pois por ser uma solução de simples aplicação, grande desempenho e vida útil em serviço de acordo com a vida útil da estrutura, certamente pode resolver e auxiliar a proteção das mais diversas estruturas, principalmente às que estão submetidas à ambientes de severa agressividade.

Pode-se concluir, através dos resultados apresentados, que por se incorporar a microestrutura do concreto, o silicato bioquimicamente modificado, possui particularidades que nos permitem entender e constatar que há uma melhora significativa na composição interna da estrutura de concreto armado, no comportamento da estrutura como um todo, influenciando diretamente no aumento da sua vida útil, reduzindo a necessidade e periodicidade de manutenabilidade da estrutura. Economizando assim o despêndio de milhões de reais em custos diretos e indiretos da iniciativa pública, privada e da própria sociedade, relacionado à intervenções para a recuperação de estruturas, gerando impacto direto na sua utilização, na redução de produtividade, influenciando diretamente na qualidade de vida da sociedade.

\section{REFERÊNCIAS}

AMERICAN SOCIETY FOR TESTING AND MATERIALS (ASTM). ASTM C12002 - Standard test method for electrical indication of concrete's ability to resist chloride ion penetration. Washington, 2018.

ASSOCIAÇÃO BRASILEIRA DE NORMAS TÉCNICAS (ABNT). NBR 12171 - Aderência aplicável em sistema de impermeabilização composto por cimento impermeabilizante e polímeros - Método de ensaio. Rio de janeiro, 2018. 
ASSOCIAÇÃO BRASILEIRAS DE NORMAS TÉCNICAS (ABNT). NBR 5739: Concreto: ensaio de compressão de corpos-de-prova cilíndricos. Rio de Janeiro, 2007.

CESÁRIO, Andressa Pelegrin. Análise do desempenho do concreto utilizado em fundações submetido à ataque por sulfato. 2015.

COSTA, Rodrigo M. Análise de Propriedades Mecânicas do Concreto Deteriorado Pela Ação de Sulfato Mediante Utilização do UPV. 2004. 246 f. Tese de Doutorado em Engenharia de Estruturas - Escola de Engenharia da Universidade Federal de Minas Gerais, Belo Horizonte, 2004.

COUTINHO, Joana de S. Materiais de Construção 1; Durabilidade - Ataque por Sulfatos. Faculdade de Engenharia da Universidade do Porto - FEUP. Porto, Portugal, 2001.

FERREIRA, Rui Miguel. Avaliação de ensaios de durabilidade do betão. 2000. Tese de Doutorado.

GJORV, O. E. Projeto da durabilidade de estruturas de concreto em ambientes de severa agressividade. Revisão técnica: FIGUEIREDO, Enio P., HELENE P.,p. 1ª, 2015.

HELENE, Paulo. A nova NB 1/2003 (NBR 6118) ea vida útil das estruturas de concreto. University of Sao Paulo PCC USP, 2003.

JIANG, Guangming; WIGHTMAN, Elaine; DONOSE, Bogdan C.; YUAN, Zhiguo; BOND, Philip L.; KELLER, Jurg. The Role of Iron in Sulfide Induced Corrosion of Sewer Concrete. 2013. Jornal Science Direct. Editora Elsevier.

LAFIN, Marcelo Kieling. Impermeabilização de estação de tratamento de efluentes de concreto armado com cimento CP-IV, utilizando silicato bioquimicamente modificado. 2015.

MCBEE, William C.; SULLIVAN, Thomas A.; JONG, Bing W. Industrial evaluation of sulfur concrete in corrosive environments. 1983.

MONTENY, Joke et al. Chemical, microbiological, and in situ test methods for biogenic sulfuric acid corrosion of concrete. Cement and Concrete Research, v. 30, n. 4, 2000.

MOREIRA, Heloisa Pimentel; FIGUEIREDO, Enio Pazini; HELENE, Paulo RL. Avaliação da influência de alguns agentes agressivos na resistência à compressão de concretos amassados com diferentes tipos de cimentos brasileiros. EPUSP, 2001.

NEVILLE, A. M. Propriedades do concreto, PINI. São Paulo, 1997.

SITTER, W.R. Costs for Service Life Optimization. The "Law of Fives". In: CEB-RILEM Durability of Concrete Structures. Proceedings of the International Workshop held in Copenhagen, 18-20 May 1983. Copenhagen, CEB, 1984. (Workshop Reported by Steen Rostam).

VON SPERLING, M. Princípio do Tratamento Biológicos de Águas Residuárias. Vol. 1: Introdução à qualidade das águas e ao tratamento de esgotos. 3 ed. Belo Horizonte: Departamento de Engenharia Sanitária e Ambiental - UFMG, 2005. 452p. 